\title{
PENERAPAN PRINSIP DESAIN RICHARD ROGERS PADA PERANCANGAN STASIUN TELEVISI LOKAL DI TEMBILAHAN
}

\author{
Arnina $^{1,}$ Yohannes Firzal ${ }^{2,}$ Gun Faisal ${ }^{3}$ \\ ${ }^{1}$ Mahasiswa Program Studi Arsitektur, Fakultas Teknik, Universitas Riau \\ ${ }^{2,3}$ Dosen Program Studi Arsitektur, Fakultas Teknik, Universitas Riau \\ email: arnina0525@student.unri.ac.id
}

\begin{abstract}
In the era of globalization, the development of information is very rapid through a variety of existing media, both print and electronic media. Television is one of media information that's widely used by the public in obtaining information. Television plays an important role in the delivery of information that can display both image and sound directly through a show. Downstream Indragiri Hilir regency is a district that has great potential in the field of tourism and agriculture so that it requires information media with adequate technology as a means to promote and introduce the potential possessed by downstream Indragiri Hilir regency. Therefore, the design of local television stations in Tembilahan with the application of the Richard Rogers design principle is expected to create television stations that can facilitate the production process and pre-production of local information with technological developments and nationals standards and can be a local media that can increase blood income through information media.
\end{abstract}

Keywords: Richard Rogers, Television stations, Tembilahan

\begin{abstract}
Abstrak
Di era globalisasi perkembangan informasi sangatlah pesat melaui berbagai macam media yang ada, baik itu media cetak maupun media elektronik. Televisi merupakan salah satu media informasi yang banyak digunakan oleh masyarakat untuk memperoleh informasi. Televisi berperan penting dalam penyampaian informasi yang dapat menampilkan gambar (visual) sekaligus suara (Audio) secara langsung melalui sebuah tayangan/siaran. Kabupaten Indragiri Hilir merupakan kabupaten yang memiliki potensi besar dalam bidang wisata dan agricultural sehingga memerlukan adanya media informasi dengan teknologi yang memadai sebagai sarana untuk mempromosikan potensi yang dimiliki oleh Kabupaten Indragiri Hilir sendiri. Oleh karena itu, rancangan Stasiun Televisi lokal di Tembilahan dengan penerapan prinsip desain Richard Rogers diharapkan dapat menciptakan stasiun televisi lokal yang dapat memfasilitasi proses produksi maupun pra-produksi informasi lokal dengan perkembangan teknologi dan berstandar nasional serta dapat menjadi media lokal yang dapat meningkatkan pendapatan daerah Indragiri Hilir.
\end{abstract}

\section{Kata-kunci : Richard Rogers, Stasiun Televisi, Tembilahan}

\section{Pendahuluan}

Pada era modern saat ini, perkembangan teknologi informasi sangat pesat dalam masyarakat. Berbagai media informasi kini telah banyak berkembang baik dari media cetak maupun elektronik. Hal ini merupakan dampak dari tuntutan kebutuhan masyarakat akan perkembangan teknologi informasi untuk memenuhi kebutuhan informasi baik informasi pendidikan, hiburan, sosial, ekonomi dan kebudayaan, pada suatu daerah. Hampir semua kalangan masyarakat menggunakan informasi dari berbagai media massa. Salah satu media yang paling banyak digunakan oleh masyarakat adalah media televisi (Abdullah, 2014). Televisi merupakan wadah penyalur informasi yang banyak digunakan saat ini. Kebutuhan informasi yang tepat dan aktual, menjadi salah satu alasan siaran televisi menjadi pilihan masyarakat. Perkembangan teknologi penyiaran melahirkan media baru yang dapat menyajikan informasi secara cepat kepada masyarakat yaitu televisi.

Menurut Riswandi (2009) televisi merupakan media yang dapat mendominasi komunikasi massa karena sifatnya yang dapat memenuhi kebutuhan dan keinginan khalayak. Televisi memiliki kelebihan dari media massa lainnya, seperti dapat streaming dan online karena bersifat audio visual (didengar dan dilihat), dapat menggambarkan kenyataan secara langsung, serta dapat menyajikan peristiwa yang sedang terjadi kepada setiap pemirsa. Di Kabupaten Indragiri Hilir sendiri belum terdapat stasiun televisi lokal sebagai sarana penyebaran informasi bagi masyarakat lokal khususnya, untuk itu perlu adanya fasilitas atau wadah yang mendukung proses produksi dan 
penyebaran informasi kepada masyarakat lokal agar mendapatkan informasi secara merata baik itu informasi pendidikan, hiburan, social, ekonomi, dan budaya lokal maupun luar yang semakin berkembang di era modern ini. Perancangan stasiun televisi di Tembilahan diharapkan dapat memberikan fasilitas sarana dan prasarana yang sesuai dalam proses program produksi informasi dibidang pertelevisian dengan penerapan tema prinsip desain Richard Rogers. Prinsip desain perancangan Richard Rogers memanfaatkan teknologi dan mesin dalam perancangan karya-karya arsitekturalnya, dengan ciri khas yang disebut inside-out. Elemen-elemen bangunan yang seharusnya diletakkan didalam interior bangunan, sebaliknya diekspos di bagian eksterior bangunan, serta dapat menampilkan kesan modern, ekspresif dan efektif pada sebuah bangunan baik pada interior dan disesuaikan dengan perkembangan teknologi material yang digunakan.

Adapun Perancangan Stasiun Televisi Lokal di Tembilahan memiliki tantangan permasalahan yaitu, Bagaimana perencanaan fasilitas-fasilitas yang sesuai untuk stasiun televisi lokal di Tembilahan, Bagaimana menerapkan tema prinsip desain Richard Rogers pada perancangan stasiun televisi lokal, Bagaimana Penerapan konsep perancangan pada stasiun televisi lokal di Tembilahan. Adapun tujuan perancangannya ialah Agar masyarakat lokal khususnya di kabupaten Indragiri Hilir mudah mendapatkan informasi serta mengetahui apasaja potensi yang tersedia dan dapat dikembangkan didaerah tersebut, Selain sebagai sarana informasi perancangan stasiun televisi lokal ini juga berfungsi untuk memberikan hiburan kepada masyarakat melalui media televisi. Pentingnya perancangan stasiun televisi dapat memberikan keuntungan dan dampak positif untuk keberlangsungan penyebaran informasi yang merata bagi setiap lapisan masyarakat, secara universal terkait dengan perkembangan teknologi yang semakin maju dan pesat, stasiun televisi juga dapat memfasilitasi penyebaran dan pengeksposan akan potensi suatu daerah agar dapat dikenal.

\section{Tinjauan Pustaka}

\section{Sekilas Arsitektur Richard Rogers}

Richard Rogers adalah seorang arsitek Inggris yang disebut sebagai salah satu pelopor dari arsitektur 'high-tech.' Rogers memanfaatkan teknologi dan mesin dalam perancangan karyakarya arsitekturalnya, dengan ciri khas yang disebut 'inside-out', dimana nampak elemen-elemen bangunan yang seharusnya diletakkan di dalam interior bangunan, sebaliknya diekpos dibagian eksterior bangunan. Richard Rogers menyatakan bahwa sebagai arsitek, ia menggunakan teknologi untuk memecahkan masalah dan untuk memberi bentuk karena jika tidak, dapat menghasilkan suatu stuktur bangunan yang tidak ada hubungannya sama sekali dengan arsitektur. Selain pentingnya peranan teknologi, Rogers memberi penekanan kepada mesin karena menurutnya, arsitek harus mengerti dan mengotrol mesin yang merupakan instrumen pembentuk bangunan dan perlu untuk terus dikembangkan. karya - karya Richard Rogers mencoba untuk mendekati image yang lebih populer dari Modernisme, yang secara esensial membungkus diri dengan fantasi teknologi (Kuwatu, 2017).

Adapun prinsip-prinsip yang digunakan oleh Richard Rogers dalam merancang adalah sebagai berikut:

1. Legibility, Prinsip ini merupakan usaha untuk membuat bangunan menjadi mudah dimengerti, tidak membingungkan, dengan struktur dan elemen - elemen bangunan yang diartikulasikan.

2. Efficiency, prinsip yang merefleksikan ambisi Rogers untuk menggunakan desain dalam membuat proses konstruksi lebih cepat, efektif, dan mengurangi biaya konstruksi termasuk biaya jangka-panjang sehingga bangunan tersebut efisien dalam operasionalnya, dengan pemanfaatan teknologi.

3. Changeability, Merupakan kemampuan bangunan yang memiliki struktur yang dapat berubah ataupun beradaptasi untuk memfasilitasi pengguna bangunan sehingga bebas berkinerja didalam ataupun diluar bangunan.

4. Flexibility, prinsip ruang - ruang fleksibel yang dapat digunakan untuk berbagai aktivitas dalam jangka pendek, sekaligus juga memiliki banyak alternatif untuk penggunaan jangka panjang yang tergantung pada kebutuhan di masa depan.

5. Lightweight, strategi yang merefleksikan kehati - hatian pemilihan material yang tepat, misalnya penggunaan material sesedikit mungkin namun tetap mencapai sasaran fungsional bangunan. Lightweigtht structure menghilangkan kesan bobot bangunan yang berat, menjadikan bangunan sebuah mesin yang ringan dengan pemanfaatan teknologi.

6. Low energy building, prinsip inovatif untuk meminimalkan polusi dan emisi karbon dan meminimalkan penggunaan energi, melalui pemanfaatan teknologi.

\section{Pengertian Stasiun Televisi}

Merupakan suatu stasiun yang menyebarkan siarannya dalam bentuk audio dan video secara bersama-sama ke televisi penerima di wilayah tertentu. Stasiun televisi terbagi kedalam beberapa jenis yaitu stasiun televisi komersial dan stasiun televisi non komersial, stasiun televisi publuk, lokal, 
serta nasional, dilihat dari cakupannya. Menurut UU penyiaran No 24 tahun 1997, bab II pasal 43, menjelakan bahwa penyiaran bertujuan untuk menumbuhkan dan mengembangkan sikap mental masyarakat indonesia yang beriman dan bertakwa kepada Tuhan Yang Maha Esa, memeperkokoh persatuan dan kesatuan bangsa, serta membangun masyarakat yang adil dan makmur. Sangat jelas tujuan secara umum adanya penyiaran televisi di Indonesia yang sudah diatur dalam UU penyiaran. Sedangkan tujuan secara khusus dimiliki oleh stasiun televisi yang bersangkutan. Pada dasarnya televisi merupakan alat atau media massa elektronik yang digunakan oleh pemilik atau pemanfaat untuk memperoleh sejumlah informasi, hiburan, pendidikan, dan lain sebagainya, Sesuai dengan UU penyiaran No 24 tahun 1997, bab II pasal 54, berbunyi " Penyiaran mempunyai fungsi sebagai media informasi dan penerangan, pendidikan, dan hiburan, yang memperkuat ideologi, politik, ekonomi, social budaya serta pertahanan dan keamanan." Menurut Wahidin (2008), banyak program acara yang disajikan oleh stasiun televisi diantaranya, mengenai sajian kebudayaan bangsa Indonesia, sehingga hal ini dapat menarik minat pemira atau penonton untuk lebih mencintai kebudayaan bangsa sendiri, sebagai salah satu warisan bangsa yang perlu dilestarikan.

\section{Metode}

Metode Perancangan

Dalam perancangan Stasiun Televisi Lokal di Tembilahan memerlukan konsep desain yang berbeda dari stasiun televisi lainya yang mencerminkan identitas daerah lokal, namun berstandar stasiun televisi nasional. Maka dirancanglah konsep Stasiun Televisi Lokal dengan tujuan untuk menjadi wadah penyebaran informasi dan pengembangan budaya lokal kepada masyarakat Kabupaten Indragiri Hilir khususnya, dengan dilengkapi fasilitas-fasilitas yang mendukung program produksi informasi, untuk itu perlu pembaharuan sesuai dengan perkembangan teknologi yang semakin canggih dengan menerapkan prinsip desain arsitek yang memanfaatkan penggunaan teknologi dan mesin dalam karya-karyanya. Richard Rogers dengan ciri khas perancangannya inside-out, dengan elemen-elemen bangunan yang seharusnya diletakkan di dalam interior bangunan, sebaliknya diekspos dibagian eksterior bangunan. Untuk lokasi perancangan Stasiun Televisi Lokal di Tembilahan ini berada di Jalan Pendidikan dekat dengan pusat pendidikan dan pusat kota Tembilahan Kabupaten Indragiri Hilir.

\section{Strategi Perancangan}

Penerapan prinsip desain Richard Rogers pada perancangan stasiun televisi lokal di Tembilahan menggunakan beberapa strategi peranangan, yaitu mencari dan mengumpulkan data studi literatur tentang penerapan arsitektur Richard Rogers pada bangunan, studi literatur pengertian dan fungsi dari stasiun televisi, melakukan survei lokasi, analisa fungsi, analisa tapak, penzoningan, kebutuhan ruang, konsep, bentukan massa, material dan struktur, interior, fasad, sirkulasi dan parkir, serta hasil desain.

\section{Metode Pengumpulan Data}

Data dikelompokkan menjadi 2 bagian; data primer yang dikumpulkan melalui pengamatan langsung terhadap obyek berupa survei lapangan dan dokumentasi yaitu berdasarkan hasil survei yang pertama, bahwa masih banyak masyarakat yang kurang mendapatkan informasi bahkan tidak ada sama sekali, khususnya masyarakat lokal perdesaan. Hasil survei yang kedua, karena tidak adanya fasilitas yang lengkap sebagai sarana produksi dan penyiaran informasi Maupun hiburan keseluruh kalangan masyarakat. Meskipun sebagian masyarakat kini telah mendapat informasi maupun hiburan dengan mudah melalui berbagai media, seperti melalui streaming dan online dengan menggunakan jaringan internet melalui telepon genggam pribadi. pada Berikut ini, bagan alur proses perancangan. 
Jurnal Arsitektur ALUR - Vol 3 No 2 September 2020

e-ISSN 2685-1490; p-ISSN 2615-1472

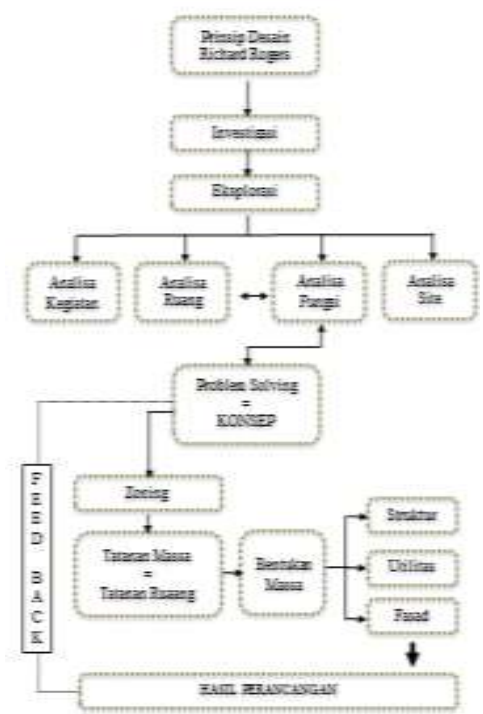

Gambar 1. Bagan alur perancangan

\section{Analisis dan Konsep Perancangan}

\section{Lokasi Perancangan}

Lokasi yang dipilih untuk perancangan stasiun televisi lokal, terletak di Kota Tembilahan, tepatnya di Jalan Pendidikan, yang memiliki batas-batas fisik tapak, yaitu utara berbatasan dengan Jalan Telaga Biru, Selatan berbatasan dengan Jalan Akasia, Barat berbatasan dengan Jalan Pendidikan, dan Timur berbatasan dengan Permukiman warga. Total Luas Tapak $\pm 1 \mathrm{Ha}(10.000$ $\mathrm{m}^{2}$ ), dengan KDB (70\%):7000 m², KDH (30\%): $3000 \mathrm{~m}^{2}$, dengan Kontur Tanah yang relatif datar dan Kondisi Eksisting merupakan lahan kosong. Perancangan stasiun televisi lokal di Tembilahan berada di Kabupaten Indragiri Hilir di Jalan Pendidikan dengan luas tapak $\pm 1 \mathrm{Ha}$. Lokasi tapak merupakan area yang strategis di pusat kota.
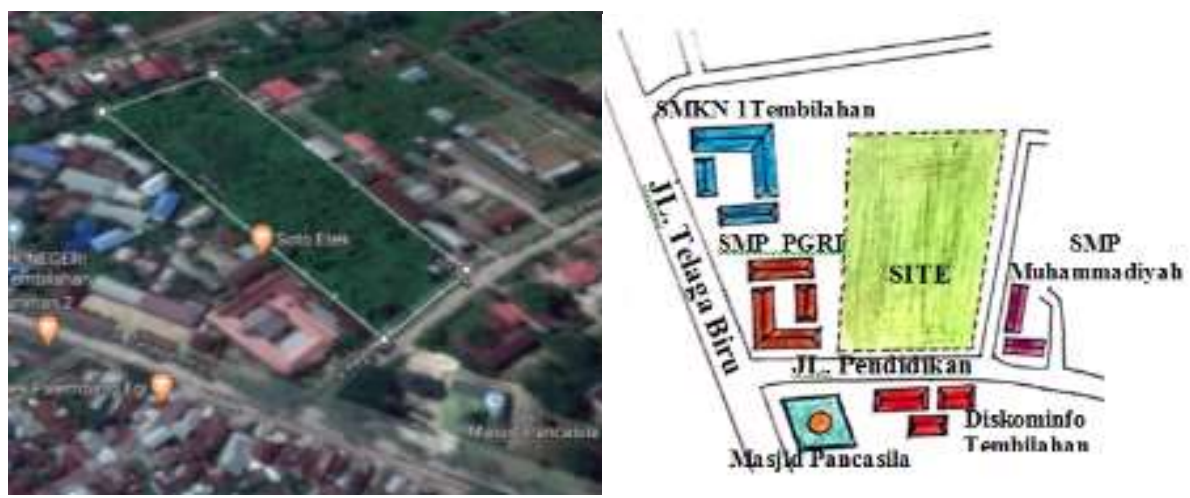

Gambar 2. Lokasi perancangan

\section{Kebutuhan Ruang}

Berdasarkan ketersedian luas tapak dan perhitungan asumsi yang berdasrkan standar besaran ruang-ruangan fungsional, maka kebutuhan luas ruangan untuk fasilitas ini dapat dikelompokkan besaran sebagai berikut:

Tabel.1 Kebutuhan Ruang

\begin{tabular}{|c|l|c|}
\hline No & \multicolumn{1}{|c|}{ Nama Ruang } & Luas \\
\hline 1 & Ruang Pelayanan Umum & $853,034 \mathrm{~m}^{2}$ \\
\hline 2 & Ruang Pengelola & $433,238 \mathrm{~m}^{2}$ \\
\hline 3 & Ruang Produksi & $4.280,9 \mathrm{~m}^{2}$ \\
\hline 4 & Ruang Servis & $265,2 \mathrm{~m}^{2}$ \\
\hline 5 & Ruang Aksesibilitas & $106,6 \mathrm{~m}^{2}$ \\
\hline 6 & Ruang Luar & $1.992,9 \mathrm{~m}^{2}$ \\
\hline \multicolumn{2}{|c|}{ Total Keseluruhan } & $7.931,872 \mathrm{~m}^{2}$ \\
\hline
\end{tabular}

Program Studi Arsitektur Universitas Katolik Santo Thomas ojs.ust.ac.id | 75 
Total luas besaran ruang keseluruhan adalah $7.931,872 \mathrm{~m}^{2}$ yang terdiri dari satu massa bangunan dengan luas ruang dalam 5.938,972 $\mathrm{m}^{2}$ dan 2.068,128 $\mathrm{m}^{2}$ luas ruang luar. Luas lahan yang tersedia \pm 1 Ha dengan KDB $70 \%$.

\section{Penzoningan}

Penzoningan ruang stasiun televisi lokal dilakukan untuk menempatkan atau mengelompokkan ruangan kedalam area yang berkesesuaian fungsinya atau sifatnya seperti:

A. Zona Publik

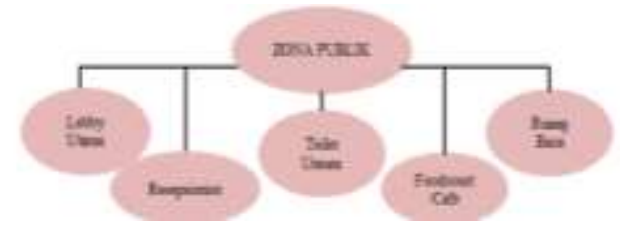

Gambar 3. Zona Publik

B. Zona Semi publik

C. Zona Privat

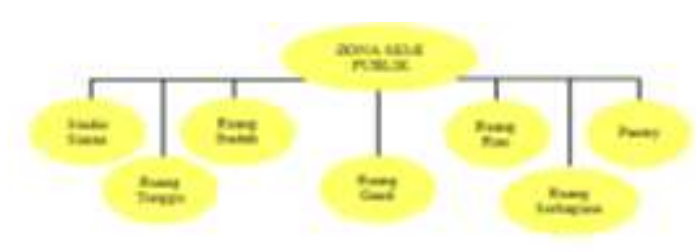

Gambar 4. Zona Semi Publik

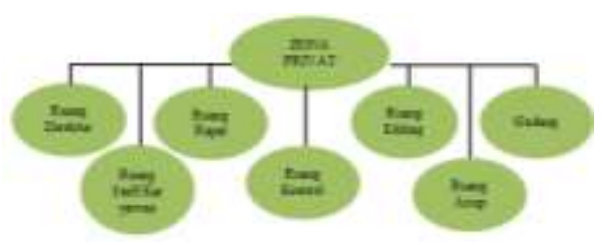

Gambar 5. Zona Privat

\section{Konsep Dasar}

Konsep dasar yang digunakan adalah technology changes, yaitu menyeimbangkan kebutuhan akan teknologi terhadap perubahan atau perkembangan teknologi pada perancangan stasiun televisi lokal. Konsep ini berkaitan erat dengan tema perancangan yakni penerapan prinsip Richard Rogers yang terkenal dengan Inside out. Prinsip-prinsip yang digunakan pada pendekatan tersebut ialah memiliki bentuk yang Legibility, Efficiency, Changeability, Flexibility, Lightweight, dan Low-energy building yang menggambarkan kedinamisan dan kefleksibelan terhadap bangunan yang dirancang yang kemudian diterapkan kedalam bangunan stasiun televisi lokal sesuai dengan kebutuhan dan perkembangan akan teknologi yang digunakan.

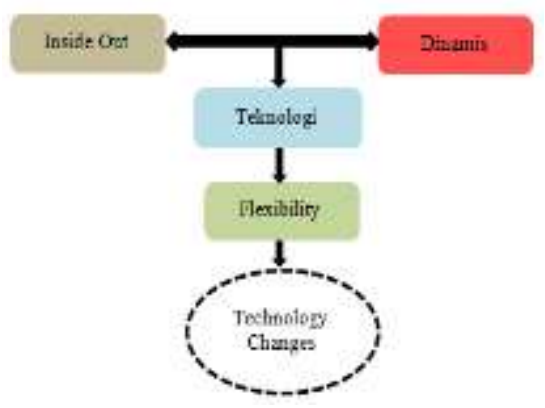

Gambar 6. Konsep Dasar

\section{Konsep Bentukan Bangunan}

Konsep bangunan merupakan pengembangan dari konsep dasar yaitu Technology changes yang berkaitan dengan fungsi rancangan sebagai sarana produksi penyiaran informasi dan hiburan, dimana dapat menghubungkan semua orang lewat kemajuan teknologi, Informasi dan hiburan bisa didapat dari televisi. Untuk itu konsep bentukan diambil dari bentuk televisi yang kemudian ditransformasikan menjadi bentuk bangunan. 
Jurnal Arsitektur ALUR - Vol 3 No 2 September 2020

e-ISSN 2685-1490; p-ISSN 2615-1472

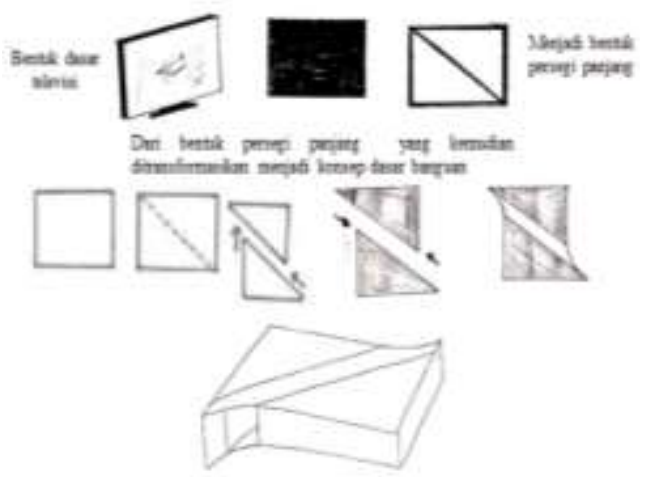

Gambar 7. Konsep Bentukan

Konsep Rencana Tapak

Rencana tapak menyesuaikan konsep dasar bangunan yaitu bidang dasar televisi berbentuk persegi panjang. Pada konsep rencana tapak, terbagi menjadi tiga zona, yaitu zona parkir, zona utama, dan zona pendukung. Zona parkir terdiri dari parkir mobil dan parkir motor, zona utama merupakan pusat kegiatan dari bangunan yaitu stasiun televisi lokal, serta zona pendukung yang terdiri dari area taman.

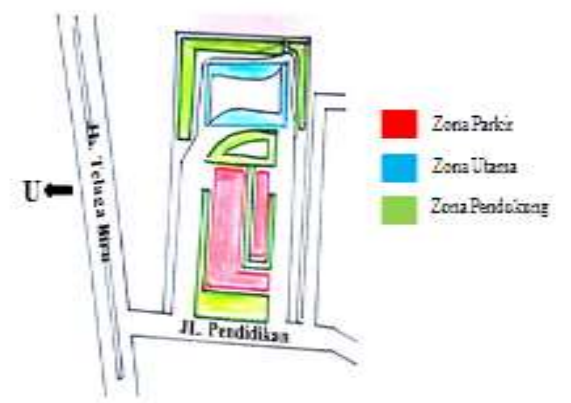

Gambar 8. Konsep Rencana Tapak

\section{Konsep Sirkulasi Dan Parkir}

Pada area parkir mobil berada di sisi kiri arah utara dan parkir sepeda motor berada disisi kanan arah selatan. Pada gambar dibawah tersebut menjelakan garis titik-titik sebagai sirkulasi untuk area pejalan kaki, warna merah ditunjukkan sebagai sirkulasi masuk kendaraan mobil dan motor, sedangkan warna biru ditunjukkan sebagai sirkulasi keluar dari site bangunan, sedangkan warna orange ditunjukkan sebagai sirkulasi servis pada bangunan.

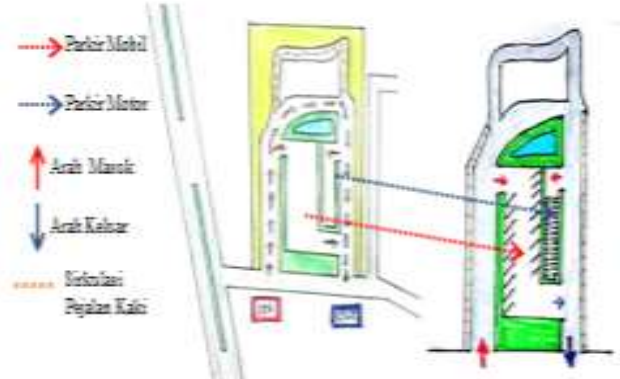

Gambar 9. Konsep Sirkulasi dan Parkir

Pencapaian

Pencapaian digambarkan melalui pencapaian jalur masuk dan keluar pada tapak dari arah barat tepatnya berada pada Jalan Pendidikan, serta terdapat dua persimpangan tiga jalan dibagian arah utara diantara jalan Telaga biru dan jalan Pendidikan, serta pada bagian selatan tapak. Pada gambar dibawah ini dijelaskan arah masuk ditandai dengan arah merah dan arah keluar ditandai dengan warna biru. 


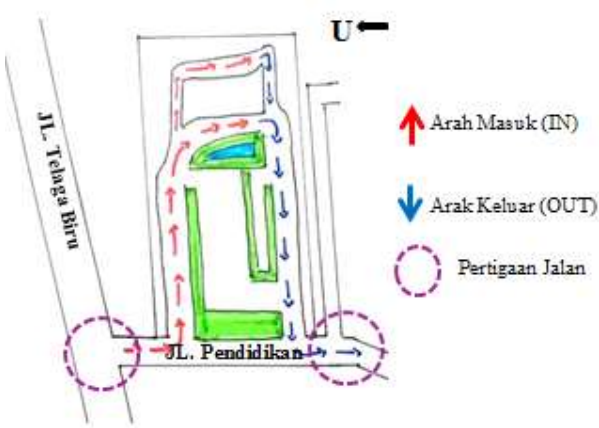

Gambar 10. Pencapaian Lokasi Perancangan

\section{Penerapan Tema}

Pada Perancangan stasiun televisi lokal ini menerapkan tema arsitektur high-tech oleh arsitek Richard Rogers dengan 6 metode prinsip perancangannya yaitu:

\section{Tabel 2. Penerapan Tema}

\begin{tabular}{|c|c|c|}
\hline No. & $\begin{array}{l}\text { Prinsip Desain } \\
\text { Richard Rogers }\end{array}$ & Penerapan \\
\hline 1 & Prinsip Legibility & $\begin{array}{l}\text { Pengeksposan struktur dan elemen-elemen pada bangunan, dan } \\
\text { Pengaplikasian warna yang memperjelas fungsi komponen atau } \\
\text { zonasi fungsional. }\end{array}$ \\
\hline 2 & Prinsip Efficiency & $\begin{array}{l}\text { penggunaan struktur pre-pabrikasi, seperti baja, beton pracetak } \\
\text { dll. }\end{array}$ \\
\hline 3 & Prinsip Changeability & $\begin{array}{l}\text { Menggunakan kerangka ruang yang bisa digabung, dikurangi, } \\
\text { dibuka, ataupun dibagi berdasarkan kebutuhan aktivitas seiring } \\
\text { berjalannya waktu. }\end{array}$ \\
\hline 4 & Prinsip Flexibility & Penerapan ruang yang bebas dan luas pada bangunan. \\
\hline 5 & Prinsip Lightweigh & $\begin{array}{l}\text { penggunaan material yang sesedikit mungkin namun tetap } \\
\text { mencapai sasaran fungsional bangunan, seperti penggunaan } \\
\text { material baja, beton, dan kaca pada desain bangunan. }\end{array}$ \\
\hline 6 & $\begin{array}{l}\text { Prinsip Low Energy } \\
\text { Building }\end{array}$ & pemanfaatan teknologi dengan menerapkan solar panel. \\
\hline
\end{tabular}

\section{Gaya Bangunan}

Gaya bangunan disesuaikan dengan fungsi perancangan sebagai tempat/wadah produksi informasi dan hiburan yang mencoba mengadaptasi prinsip desain Richard Rogers.

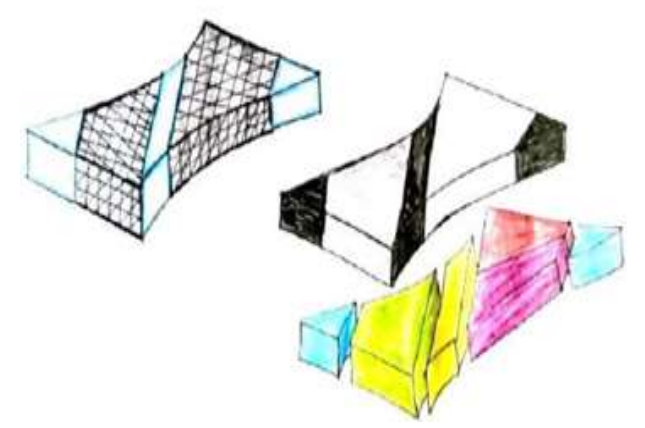

Gambar 11. Gaya Bangunan

\section{Gubahan Massa}

Pada perancangan stasiun televisi lokal di Tembilahan ini bentuk bangunan disesuaikan dengan bangunan modern yang menampilkan struktur yang ekspresif dan menggambarkan prinsip desain bangunan Richard Rogers. Serta menyesuaikan fungsi bangunan. 

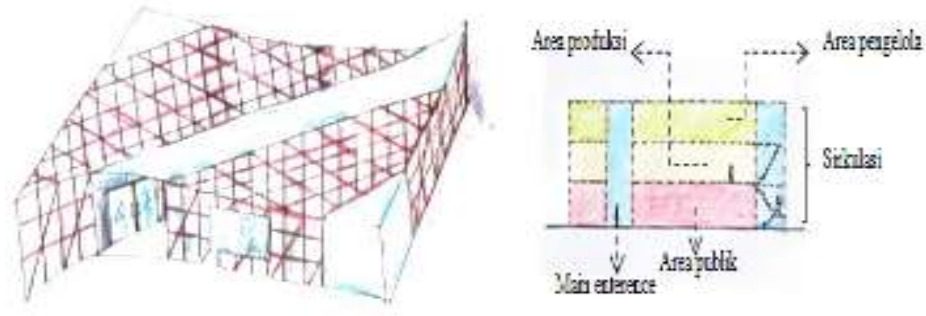

Gambar 12. Gubahan Massa

Fasad

Fasad bangunan dilapisi kaca dan dinding kaca sehingga dapat memasukkan cahaya dari luar kedalam bangunan dengan lebih mudah.

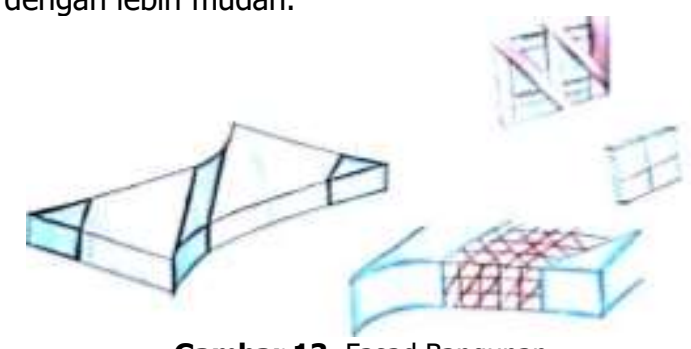

Gambar 13. Fasad Bangunan

Interior

Interior bangunan dirancang dengan ruang yang luas dan fleksibel, sehingga dapat memudahkan pengguna ruang yang bekerja didalam bangunan sesuai dengan aktivitas yang dilakukan. Salah satu bagian ruang utama pada bangunan yang merupakan area produksi yaitu news room dan studio siaran.

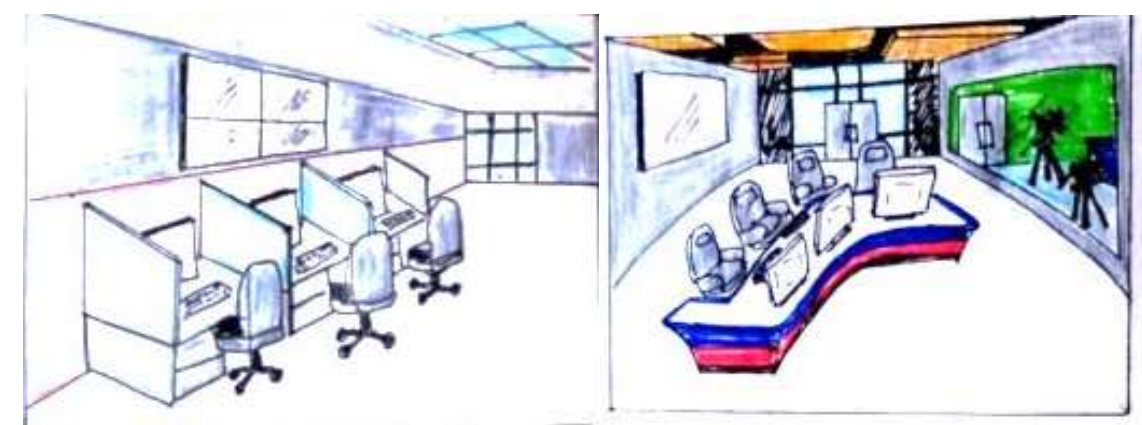

Gambar 14. News Room dan Studio Siaran

\section{Warna dan Material}

Pemilihan warna dan material disesuaikan dengan prinsip Desain Richard Roger yang menerapkan warna dominan dalam nuansa putih, hitam dan abu-abu. Warna putih lebih banyak digunakan pada elemen interior dinding dan plafond, sedangkan warna hitam digunakan pada lantai, dan pemakain warna abu-abu cenderung digunakan pada eksterior bangunan. Sedangkan material yang digunakan ialah beton, baja, dan kaca, serta material pendukung lainnya seperti Material Aluminium composit panel (ACP).

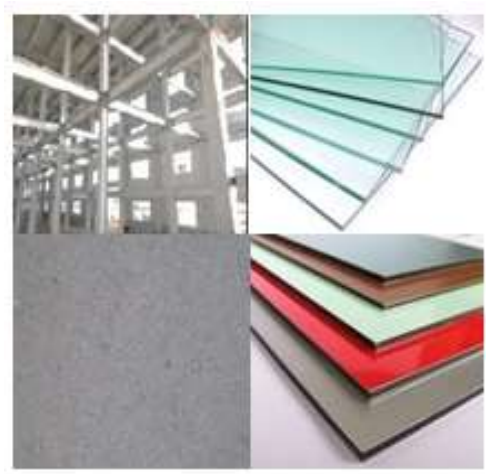

Gambar 15. Warna dan Material yang digunakan

Program Studi Arsitektur Universitas Katolik Santo Thomas ojs.ust.ac.id |79 
Vegetasi

Konsep pemiihan jenis vegetasi didasarkan atas pertimbangan desain, yaitu menggunakan tanaman peneduh, pengarah, dan pembatas yang digunakan sebagai vegetasi pada bangunan sekitar.
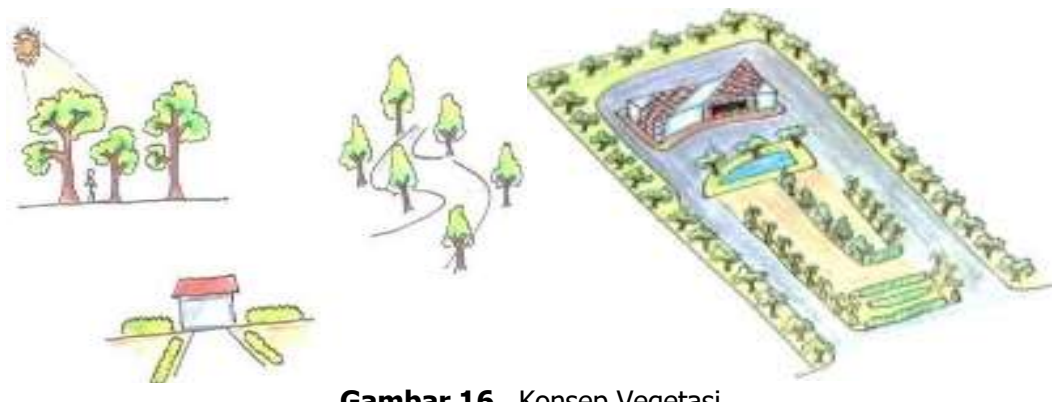

Gambar 16. Konsep Vegetasi

\section{Kesimpulan dan Saran}

Kesimpulan yang didapat dalam perancangan ini ialah fungsi yang diterapkan pada rancangan ini sesuai sebagai tempat produksi informasi dan hiburan, Pemilihan lokasi dengan jarak tempuh singkat dan berdekatan dengan pusat kota, telah memperkuat penerapan konsep desain technology changes dengan mengadaptasi prinsip desain Richard Rogers melaui penerapan 6 prinsip desain; yaitu Legibility, Efficiency, Changeability, Flexibility, Lightweight, dan Low-energy building. Pengaplikasian konsep dan pendekatan arsitektur yang dipilih ke rancangan bangunan telah menghasilkan suatu bentukan yang dinamis dan fleksibel serta menggambarkan bangunan yang modern dan berbeda tetapi tetap menyesuaikan bangunan disekitarnya.

Penulis sangat mengharapkan saran dan kritikan yang dapat membangun dari pembaca, sehingga dapat menghasilkan penulisan yang lebih baik serta maksimal dan dapat menjadi pedoman bagi yang lainnya, khususnya mahasiswa arsitektur.

\section{Daftar Pustaka}

Abdullah, Muhajir. 2014. Stasiun Televisi Swasta Makassar. Skripsi Program Studi Arsitektur, Universitas Islam Negeri Alauddin Makassar. Makassar.

Edgar E. Willis, Henry B. Aldridge. 1991. Televison, Cable and Radio: A Communication Approach. Prentice-Hall.

Effendy, Onong Uchjana. 2000. IImu Teori dan filsafat Komunikasi. PT. Citra Aditya Bakti. Bandung. Jencks, Charles. 1990. High Tech Maniera. Academy Edition.

Kawatu, E, Freike. 2017. Aplikasi Bangunan High-Tech Dalam Teori Perancangan Richard Rogers. Universitas Negeri Manado. Manado.

Riswandi. 2009. Dasar-dasar Penyiaran. Penerbit Graha Ilmu. Yogyakarta.

Rogers, R., 2011, Richard Rogers and Architects: From the House to the City, Fiell Publishing 